\title{
Impact of cardiovascular magnetic resonance assessment of ejection fraction on eligibility for implantable cardioverter defibrillators
}

\author{
Subodh B Joshi ${ }^{1 *}$, Kim A Connelly ${ }^{1}$, Mark Hansen², Sean McSweeney ${ }^{1}$, Jerome Liu', Yuesong Yang ${ }^{2}$, \\ Laura Jimenez-Juan ${ }^{3}$, Abdul Al-Hesayen ${ }^{1}$, Iqwal Mangat ${ }^{1}$, Paul Dorian ${ }^{1}$, Graham A Wright ${ }^{2}$, Andrew Crean $^{3}$, \\ Anish Kirpalani ${ }^{1}$, Andrew T Yan ${ }^{1}$, Howard Leong-Poi ${ }^{1}$
}

From 2011 SCMR/Euro CMR Joint Scientific Sessions

Nice, France. 3-6 February 2011

\section{Objective}

To determine whether cardiovascular magnetic resonance (CMR) for left ventricular ejection fraction (LVEF) assessment changes implantable cardioverter defibrillator (ICD) eligibility when compared with echocardiography.

\section{Background}

A markedly reduced LVEF is considered an indication for ICD placement for the primary prevention of sudden cardiac death. However, despite strict LVEF criteria, most guidelines do not specify the technique by which LVEF should be measured.

\section{Methods}

The study population consisted of patients referred for LVEF measurement by CMR, for consideration of ICD implantation, who also underwent echocardiography within 30 days of the CMR. LVEF was assessed on echocardiography using Simpson's biplane method. LVEF was determined from CMR based on manual planimetry of SSFP cine images of contiguous left ventricular short axis slices. CMR and echocardiography derived LVEFs were reported by two independent blinded observers.

\section{Results}

Forty-nine (49) eligible patients were identified (10 female, mean age $61+/-15$ years, 24 with ischemic etiology) who underwent CMR between March 20, 2007

${ }^{1}$ St Michael's Hospital, Toronto, ON, Canada

Full list of author information is available at the end of the article and Aug 12, 2010. The median number of days between CMR and echo was 3 (IQR 1 to 10 days). The mean LVEF by CMR and echo was $31+/-15 \%$, and $34+/-$ $15 \%$, respectively, $(\mathrm{p}=0.009)$, with a correlation coefficient $(r)$ between the two of 0.86 . Using Bland Altman analysis, the mean difference (CMR - echo) was - $3.1 \%$ with limits of agreement of - 18 to $12 \%$. CMR resulted in reclassification regarding ICD eligibility in $10(20 \%)$ patients using an LVEF threshold of $35 \%$, and 8 (16\%) using an LVEF threshold of $30 \%$. Tables 1 and 2 .

\section{Conclusion}

In this cohort of patients being considered for ICD implantation, echocardiography systematically overestimated LVEF. Using strict LVEF criteria, CMR changed the eligibility for ICD in a substantial proportion of patients, with, in most cases, CMR determining that the

Table 1 LVEF Threshold $30 \%$

\begin{tabular}{llll}
\hline & Echo LVEF $>=\mathbf{3 0} \%$ & Echo LVEF $<\mathbf{3 0 \%}$ & Total \\
\hline CMR LVEF $>=30 \%$ & 21 & 1 & 22 \\
CMR LVEF $<30 \%$ & 7 & 20 & 27 \\
Total & 28 & 21 & 49 \\
Kappa $=0.68$ & & & \\
\hline
\end{tabular}

Table 2 LVEF Threshold 35\%

\begin{tabular}{llll}
\hline & Echo LVEF $>=\mathbf{3 5} \%$ & Echo LVEF $<\mathbf{3 5 \%}$ & Total \\
\hline CMR LVEF $>=35 \%$ & 15 & 3 & 18 \\
CMR LVEF $<35 \%$ & 7 & 24 & 31 \\
Total & 22 & 27 & 49 \\
Kappa $=0.58$ & & &
\end{tabular}

Kappa $=0.58$ 
patient was ICD eligible when they were not based on echocardiography.

\section{Author details}

${ }^{1}$ St Michael's Hospital, Toronto, ON, Canada. ${ }^{2}$ Sunnybrook Health Sciences

Centre, Toronto, ON, Canada. ${ }^{3}$ Toronto General Hospital, Toronto, ON,

Canada.

Published: 2 February 2011

doi:10.1186/1532-429X-13-S1-032

Cite this article as: Joshi et al:: Impact of cardiovascular magnetic

resonance assessment of ejection fraction on eligibility for implantable cardioverter defibrillators. Journal of Cardiovascular Magnetic Resonance 2011 13(Suppl 1):032.

Submit your next manuscript to BioMed Central and take full advantage of:

- Convenient online submission

- Thorough peer review

- No space constraints or color figure charges

- Immediate publication on acceptance

- Inclusion in PubMed, CAS, Scopus and Google Scholar

- Research which is freely available for redistribution

Submit your manuscript at www.biomedcentral.com/submit
() Biomed Central 